\title{
Immunomodulatory Effect of Doxycycline Ameliorates Systemic and Pulmonary Inflammation in a Murine Polymicrobial Sepsis Model
}

\author{
Anasuya Patel, ${ }^{1,2}$ Hemant Khande, ${ }^{2}$ Hariharan Periasamy, ${ }^{2}$ and Santosh Mokale $\mathbb{D}^{1,3}$
}

\begin{abstract}
Acute lung injury is an inflammatory condition developed after severe sepsis in response to excessive secretion of pro-inflammatory cytokines. Doxycycline is widely reported to possess immunomodulatory activity through inhibition of various inflammatory pathways. Considering the broad spectrum of anti-inflammatory activity, protective effect of doxycycline was evaluated in clinically relevant murine polymicrobial sepsis model induced by caecal ligation and puncture (CLP). In this model, sepsis is accompanied with infection and therefore ceftriaxone at sub-protective dose was combined to retard the bacterial growth. Three hours after CLP challenge, mice were administered vehicle, ceftriaxone $(100 \mathrm{mg} / \mathrm{kg}$ subcutaneously) alone and in combination with immunomodulatory dose of doxycycline $(50 \mathrm{mg} / \mathrm{kg}$, intraperitoneal) and survival were monitored for 5 days. Bacterial count in blood and peritoneal fluid along with cytokines [interleukin (IL)-6, IL-1 $\beta$, tumour necrosis factor (TNF)- $\alpha$ ] and myeloperoxidase (MPO) in plasma and lung homogenate were measured at $18 \mathrm{~h}$ post-CLP. Plasma glutathione (GSH) was also determined. Doxycycline in presence of ceftriaxone improved survival of septic mice by significantly reducing the plasma and lung pro-inflammatory cytokines and MPO levels. It also increased plasma GSH levels. Doxycycline did not improve antibacterial effect of ceftriaxone in combination, suggesting that the protective effect of doxycycline was due to its immunomodulatory activity. Doxycycline in the presence of ceftriaxone demonstrated improved survival of septic mice by modulating the immune response.
\end{abstract}

KEY WORDS: polymicrobial sepsis; inflammation; cytokines; survival; bacterial count.

\footnotetext{
${ }^{1}$ Y.B. Chavan College of Pharmacy, Dr. Rafiq Zakaria Marg, Aurangabad, Maharashtra, India

${ }^{2}$ Wockhardt Research Centre, Aurangabad, Maharashtra, India

${ }^{3}$ To whom correspondence should be addressed at Y.B. Chavan College of Pharmacy, Dr. Rafiq Zakaria Marg, Aurangabad, Maharashtra, India. Email: santoshmokale@ rediffmail.com
}

\section{INTRODUCTION}

Acute lung injury secondary to severe sepsis is a major cause of early mortality in hospitalised patients diagnosed with pneumonia or other bacterial infections $[1,2]$. Despite of advanced treatment options, the mortality rate reported from acute lung injury is $30-50 \%$ [3]. Sepsis is a hyper-inflammatory condition manifested due to excessive secretion of pro-inflammatory cytokines and other 
inflammatory mediators in response to exotoxin or endotoxin released by bacteria $[4,5]$. Uncontrolled levels of these cytokines along with free oxygen species and MPO released by neutrophils have been linked to organ dysfunction and mortality in sepsis [6-8]. Neutrophils are also known to release matrix metalloproteinase (MMPs) such as MMP-2 and MMP-9 that in excess amount are reported to cause degradation of extracellular matrix of endothelial basement membrane, disrupt resident cells and instigate further inflammation $[9,10]$.

The primary action for management of sepsis is to timely treat patients with effective antibiotics. Since sepsis is an inflammatory condition, therapies modulating host immunity are also under clinical investigation to manage the secondary complications associated with sepsis [11]. Tetracycline antibacterial agents such as minocycline and doxycycline have been widely reported to exhibit antiinflammatory action. As a result of this activity, tetracyclines have displayed clinical benefits in the treatment of acute and chronic inflammatory disorders, including gingivitis, periodontitis, rheumatoid arthritis, osteoarthritis, skin infections and acute respiratory distress syndrome [12-14]. Milano et al. and Agostino et al. had earlier reported survival benefit of doxycycline in LPS-induced sepsis in mice through significant reduction in TNF- $\alpha$, IL$1 \alpha$ and inducible nitric oxide synthase $[15,16]$. Sun et al. had demonstrated suppression of cytokines and chemokines production by doxycycline in LPSstimulated THP-1 cell lines via modulating the phosphorylation of the NF-KB, p38 and ERK1/2/MAPK pathways [17]. Few earlier studies have also demonstrated the beneficial effect of doxycycline on Influenza virus, allergen and bleomycin induced acute lung injury through inhibition of MMP-2 and MMP-9 [9, 18]. Doxycycline in combination with ceftriaxone has been earlier reported to ameliorate neuroinflammation and survival of rats affected with pneumococcal meningitis [19]. Clinically doxycycline was found to reduce the serum levels of IL-6, IL-1 $\beta$ and TNF- $\alpha$ in patients with dengue hemorrhagic fever [20].

Considering comprehensive anti-inflammatory profile of doxycycline, the present study aimed to investigate the immunomodulatory effect of doxycycline (belonging to tetracycline class) in a widely preferred, clinical relevant murine CLP-induced polymicrobial sepsis model [21]. Compared with LPS, the cytokine release profile following CLP sepsis closely resembles with that of human [22]. This is a first ever study undertaken to examine the survival benefit of doxycycline in combination with ceftriaxone in a CLP sepsis model. Although, doxycycline possesses antibacterial activity towards few strains of enteric bacteria, its bacteriostatic effect may not provide advantage in controlling the bacterial growth after CLP intervention. Therefore, in this study, doxycycline was combined with ceftriaxone (a third-generation broad spectrum cephalosporin antibiotic) to rapidly control the infection caused due to enteric bacteria.

\section{MATERIALS AND METHODS}

All the experimental protocols were agreed by the Institutional Animals Ethics Committee (IAEC) of Wockhardt Research Centre, India. Female Swiss albino mice, weighing 25-30 g, were used for the entire study. Mice were housed in cages with standard rodent feed and drinking water supplied ad libitum. The light cycle was controlled automatically (on at 7:00 a.m. and off at 7:00 p.m.), and the room temperature was regulated to 18 $22{ }^{\circ} \mathrm{C}$ with $40-70 \%$ humidity. Before initiating the CLP sepsis model, the immunomodulatory dose of doxycycline was identified based on survival response in LPS model as described earlier [23].

\section{CLP-Induced Sepsis Model}

CLP technique as described previously was followed for the study [24]. Mice were made unconscious using ketamine/xylazine $(100 / 10 \mathrm{mg} / \mathrm{kg}$, i.p. $)$, abdomen was disinfected and a small mid-abdominal incision was made to expose the cecum just distal to the ileocecal valve. After isolating the caecum, it was ligated with a 3-0 silk suture without disrupting the bowel flow and then pierced through twice with an 18-gauge needle. To ensure the patency of the punctured portion, cecum was gently squeezed to extrude small amount of faeces. The punctured cecum was carefully placed back into the abdomen, and the incision was closed with sutures. The mice were then resuscitated with $1 \mathrm{~mL}$ of sterile saline injected subcutaneously and returned to their cages with free access to feed and water. Sham-operated controls underwent similar procedure, but without ligation and puncture. The survival of mice was monitored for 5 days. In a separate study, parameters like plasma and lung cytokines and MPO, plasma GSH and bacterial count in blood, peritoneal fluid and lung homogenate were measured after $18 \mathrm{~h}$ of CLP challenge.

\section{Treatment Group for the CLP-Induced Sepsis Model}

From the initial survival studies performed in mice that had undergone CLP (data not shown), it was determined that a sub-protective dose of ceftriaxone 
(100 mg/kg s.c.) provided protection in $37.5 \%$ of mice. The survival study ( $n=8 \mathrm{mice} /$ group) included a sham-treated group, CLP-challenged mice treated with vehicle (saline), ceftriaxone (100 mg/kg s.c.), doxycycline (immunomodulatory dose selected from the LPS sepsis model), or both ceftriaxone $(100 \mathrm{mg} / \mathrm{kg}$ s.c. $)$ and an immunomodulatory dose of doxycycline in combination. For the estimation of biochemical and other parameters, the groups included were sham-treated control and CLP-challenged mice treated with vehicle (saline), ceftriaxone (100 mg/kg s.c.) and ceftriaxone (100 mg/kg s.c.) plus doxycycline (immunomodulatory dose). For the biochemical estimations, each group consisted of fourteen mice. Vehicle and drug treatments were done only once at $3 \mathrm{~h}$ post-CLP procedure.

\section{Experimental Protocol}

To obtain plasma for estimation of cytokines, MPO and GSH levels, the mice $(n=14)$ were bled through the retro orbital sinus and the blood was collected in heparinised tubes to obtain plasma. The plasma samples from six mice were stored for estimation of cytokines and of remaining eight mice were used for the estimation of MPO and GSH. In addition, lungs harvested from CLPchallenged mice were rinsed with saline, dried and weighed. Lungs $(n=6)$ were homogenised with chilled saline and centrifuged at $15,000 \mathrm{rpm}$ for $10 \mathrm{~min}$ at $4{ }^{\circ} \mathrm{C}$ to obtain supernatant for cytokine measurements. Further, lungs from remaining eight mice were homogenised with $50 \mathrm{mM}$ potassium phosphate buffer ( $\mathrm{pH}$ 6.0) containing $0.5 \%$ hexadecyltrimethylammonium bromide, sonicated and centrifuged to obtain supernatant for MPO estimation.

\section{Estimation of Cytokine Levels}

TNF- $\alpha$, IL-6 and IL- $1 \beta$ were estimated using commercially available enzyme-linked immunosorbent assays (ELISAs), according to the manufacturer's instruction ( $\mathrm{R}$ \& D Systems Inc., USA).

\section{Measurement of MPO Activity and GSH Content}

MPO activity was determined by o-dianisidine method and GSH was estimated using Ellman's reagent [5, 5'Dithiobis (2-nitrobenzoic acid) or DTNB] with modification for 96-well plate as described previously [23]. For MPO estimation, absorbance was recorded at $460 \mathrm{~nm}$ per minute for period of $10 \mathrm{~min}$ and for GSH estimation, the absorbance was read after 10-min incubation at $412 \mathrm{~nm}$ following addition of all reagents using spectrophotometer (SpectraMax ${ }^{\circledR}$ Plus 384 Microplate Reader). One unit of
MPO was defined as that degrading $1 \mu \mathrm{mol}$ of hydrogen peroxide per minute at $25^{\circ} \mathrm{C}$. A molar extinction coefficient of $10,062 \mathrm{M}^{-1} \mathrm{~cm}^{-1}$ of oxidised o-dianisidine was used for calculation. MPO activity was expressed in $\mu \mathrm{M} /$ $\mathrm{min} / \mathrm{mL}$ of plasma and in $\mu \mathrm{M} / \mathrm{min} / \mathrm{g}$ of tissue. The $\mathrm{GSH}$ concentration was estimated using a standard curve constructed with different concentrations of L-glutathione (Sigma-Aldrich).

\section{Evaluation of Bacterial Clearance}

Bacterial loads were estimated in blood, peritoneal lavage fluid and lung homogenate at $18 \mathrm{~h}$ post-CLP. Blood samples were collected from each mouse in heparinised tubes, mixed and placed on ice bath. Mice were then anaesthetised with ketamine/xylazine solution and injected with $2 \mathrm{~mL}$ of sterile saline intraperitoneally. Abdomen was gently massaged, disinfected with $70 \%$ alcohol and cut open to expose the peritoneal cavity to collect the peritoneal lavage fluid. Lungs were then harvested and homogenised using sterile saline to prepare $20 \%$ homogenate. Blood, peritoneal lavage fluids and lung homogenate $(100 \mu \mathrm{L})$ were kept on ice and diluted serially with sterile saline. Ten microlitres of each diluted samples was placed on trypticase soy agar plates (BD Biosciences, San Diego, CA) and incubated at $37^{\circ} \mathrm{C}$ for $24 \mathrm{~h}$. The bacterial colonies were then counted and expressed as colony-forming units (CFU) per millilitre of blood and peritoneal lavage and per milligram of tissue.

\section{Statistics}

Survival data were analysed using the log-rank test. Data were represented as mean \pm S.E.M. Differences among groups were assessed using one-way analysis of variance (ANOVA) test, followed by Dunnett's multiple comparison post hoc test. Probability of $P<0.05$ was considered to be significant. All statistical analysis were performed using Graph pad prism statistical software (version 5).

\section{RESULTS}

\section{Survival}

In the LPS-induced sepsis model (data not shown), doxycycline 50 and $100 \mathrm{mg} / \mathrm{kg}$ were identified as immunomodulatory doses (63\% survival). Further immunomodulatory effect of doxycycline in LPS sepsis model was confirmed through significant inhibition of plasma cytokines, MPO and GSH levels (data not shown). Based on 
this finding, doxycycline dose of 50 and $100 \mathrm{mg} / \mathrm{kg}$ was selected for the subsequently performed CLP model.

Doxycycline 50 and $100 \mathrm{mg} / \mathrm{kg}$ dose groups were initially studied for survival benefit in the CLP sepsis model where untreated CLP control group showed $100 \%$ mortality by $24 \mathrm{~h}$. Contrary to the observation with LPS-induced sepsis model, only a modest $25 \%$ survival rate was noted with $50 \mathrm{mg} / \mathrm{kg}$ dose while the higher dose $100 \mathrm{mg} / \mathrm{kg}$ showed no further improvement (data not shown). When ceftriaxone, a broad spectrum cephalosporin antibiotic, was combined at a sub-protective dose of $100 \mathrm{mg} / \mathrm{kg}$, s.c. with both the doses of doxycycline, a significant survival rate $(P<0.001)$ was observed with lower $50 \mathrm{mg} / \mathrm{kg}$ dose $(75 \%)$ but higher dose combination was associated with no survival. The protective effect observed with lower dose of doxycycline and ceftriaxone combination was significantly superior to standalone ceftriaxone $(37.5 \%)$. Therefore, in order to evaluate the immunomodulatory effect, subsequent studies were undertaken with lower dose combination (Fig. 1).

\section{Plasma Cytokines}

Significant increase in the plasma levels of TNF- $\alpha$ $(129.5 \pm 14.4 \mathrm{pg} / \mathrm{mL} ; P<0.001)$, IL-6 $(14,743.3 \pm$ $1603.3 \mathrm{pg} / \mathrm{mL} ; P<0.001)$ and IL-1 $\beta(207.2 \pm 33.2 \mathrm{pg} /$ $\mathrm{mL} ; P<0.001)$ was observed in the CLP-challenged group compared with sham control (TNF- $\alpha, 7.57 \pm 1.1 \mathrm{pg} / \mathrm{mL}$; IL-6, $37.96 \pm 6.4 \mathrm{pg} / \mathrm{mL}$; and IL-1 $\beta, 13.88 \pm 2.1 \mathrm{pg} / \mathrm{mL})$. Ceftriaxone $(100 \mathrm{mg} / \mathrm{kg}$, s.c. $)$ and ceftriaxone + doxycycline combination $(100 \mathrm{mg} / \mathrm{kg}$, s.c. $+50 \mathrm{mg} / \mathrm{kg}$, i.p. $)$ showed significant inhibition of plasma cytokine concentrations. The levels of plasma TNF- $\alpha$, IL- 6 and IL- $1 \beta$ in the ceftriaxone group were $51.9 \pm 3.5(P<0.001), 981.2 \pm$ $136.3(P<0.001)$ and $70.5 \pm 7.2(P<0.001) \mathrm{pg} / \mathrm{mL}$ and in combination group were $25.4 \pm 1.7(P<0.001), 650 \pm 47.6$ $(P<0.001)$ and $36.8 \pm 7.2(P<0.001) \mathrm{pg} / \mathrm{mL}$, respectively (Fig. 2). Interestingly, the favourable effect of ceftriaxone on plasma cytokines was not associated with the survival benefit, unlike that observed with combination group.

\section{Lung Cytokines}

The lung levels of TNF- $\alpha$, IL- 6 and IL- $1 \beta$ in the CLP-challenged group were $246.8 \pm 49.1,481.2 \pm 99.8$ and $542.9 \pm 36.1 \mathrm{pg} / \mathrm{mL}$, respectively. These cytokines were undetectable in the sham group due to levels below quantification. Ceftriaxone treatment did not significantly alter the cytokine levels; however, the combination group demonstrated significant $(P<0.05)$ reduction in their levels (TNF- $\alpha, 73.6 \pm 6.4$; IL-6, $97.4 \pm 16.7$; and IL-1 $\beta$, $368.1 \pm 27.3 \mathrm{pg} / \mathrm{mL}$ ) (Fig. 3).

\section{GSH Levels and MPO Activity}

Plasma GSH content in the CLP-challenged mice was $1.01 \pm 0.09 \mathrm{mg} / \mathrm{mL}$, significantly $(P<0.001)$ lower than the level $2.13 \pm 0.18 \mathrm{mg} / \mathrm{mL}$ observed in the sham group. Ceftriaxone had no effect on the GSH concentration but the combination group showed significantly increased level $(2.00 \pm 0.16 \mathrm{mg} / \mathrm{mL} ; P<0.001)$. The MPO activity in plasma and lung of vehicle-treated CLP group at $18 \mathrm{~h}$ post-CLP was $648.2 \pm 43.6 \mu \mathrm{M} / \mathrm{min} / \mathrm{mL}$ and $67.62 \pm$ $5.0 \mu \mathrm{M} / \mathrm{min} / \mathrm{g}$, respectively. These levels were significantly $(P<0.001)$ higher than that of sham control. Ceftriaxone showed no effect on the MPO activity while combination group exhibited significantly reduced MPO both in plasma $(225.9 \pm 23.9 \mu \mathrm{M} / \mathrm{min} / \mathrm{mL} ; P<0.001)$ and lung $(39.9 \pm$ $4.7 \mu \mathrm{M} / \mathrm{min} / \mathrm{g} ; P<0.001$ ) (Fig.4).

\section{Bacterial Count in Blood, Peritoneal Lavage Fluid and Lung Homogenate}

In order to verify whether the protective effect of combination group was due to synergistic antibacterial activity, the bacterial count was determined at $18 \mathrm{~h}$ postCLP in the blood, peritoneal fluid and lung homogenate. CLP mice treated with vehicle demonstrated significant increase in bacterial count. Mice treated with ceftriaxone at $100 \mathrm{mg} / \mathrm{kg}$ by s.c. route showed significant reduction in bacterial count in blood, peritoneal fluid and lung homogenate. However, doxycycline $(50 \mathrm{mg} / \mathrm{kg}$, i.p. $)$ in combination did not further improve the antibacterial activity of ceftriaxone, thus suggesting that doxycycline had no antibacterial activity against the microorganisms (Fig. 5).

\section{DISCUSSION}

In the present study, the immunomodulatory effect of doxycycline in combination with ceftriaxone was demonstrated by significant reduction of systemic as well as pulmonary inflammation in a murine CLP-induced sepsis model. It should be noted that higher incidences of mortality in intensive care settings are primarily associated with acute respiratory distress syndrome resulting from acute lung injury caused due to either direct (pneumonia) or indirect lung injury (non-pulmonary sepsis or trauma) [25].

Excessive secretion of pro-inflammatory cytokines in response to toxins released by bacteria has been widely implicated in sepsis-induced organ dysfunction [26]. The pro-inflammatory cytokines such as IL-1 $\beta$, IL- 6 and TNF$\alpha$ are markedly elevated during early phase of sepsis and play crucial role in regulating the progression of sepsis 


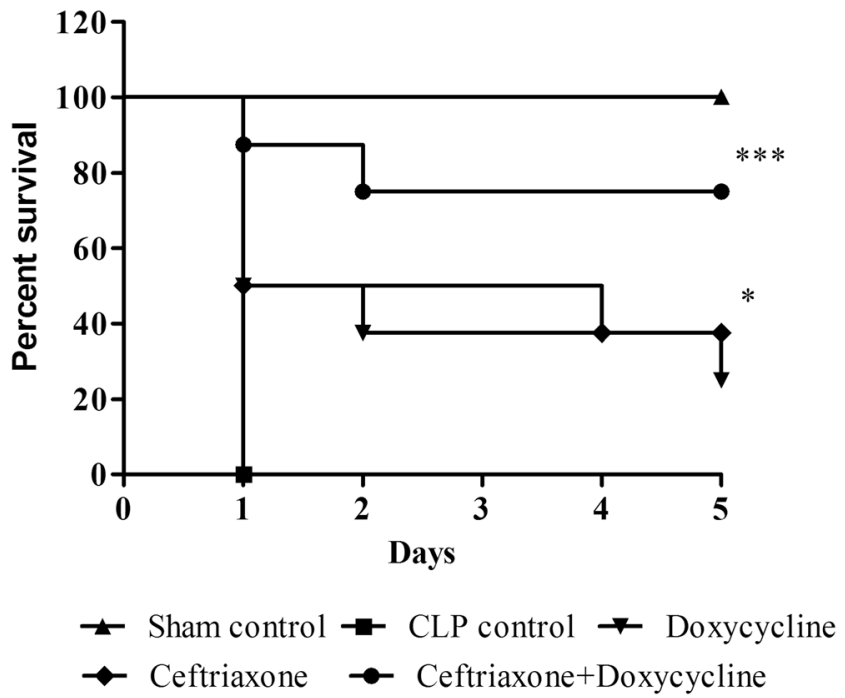

Fig. 1. Effect of doxycycline on survival of mice ( $n=8 /$ group $)$ in CLP-induced sepsis model. In the CLP sepsis model, ceftriaxone (100 mg $/ \mathrm{kg}$, s.c.), doxycycline $(50 \mathrm{mg} / \mathrm{kg}$, i.p.) and both in combination [ceftriaxone $(100 \mathrm{mg} / \mathrm{kg}$, s.c.) + doxycycline $(50 \mathrm{mg} / \mathrm{kg}$, i.p.)] were administered $3 \mathrm{~h}$ after CLP and survival of mice was monitored for 5 days. Statistical analysis was performed using log-rank test. $* P<0.05$ or $* * * P<0.001$ for significance versus CLP control group.
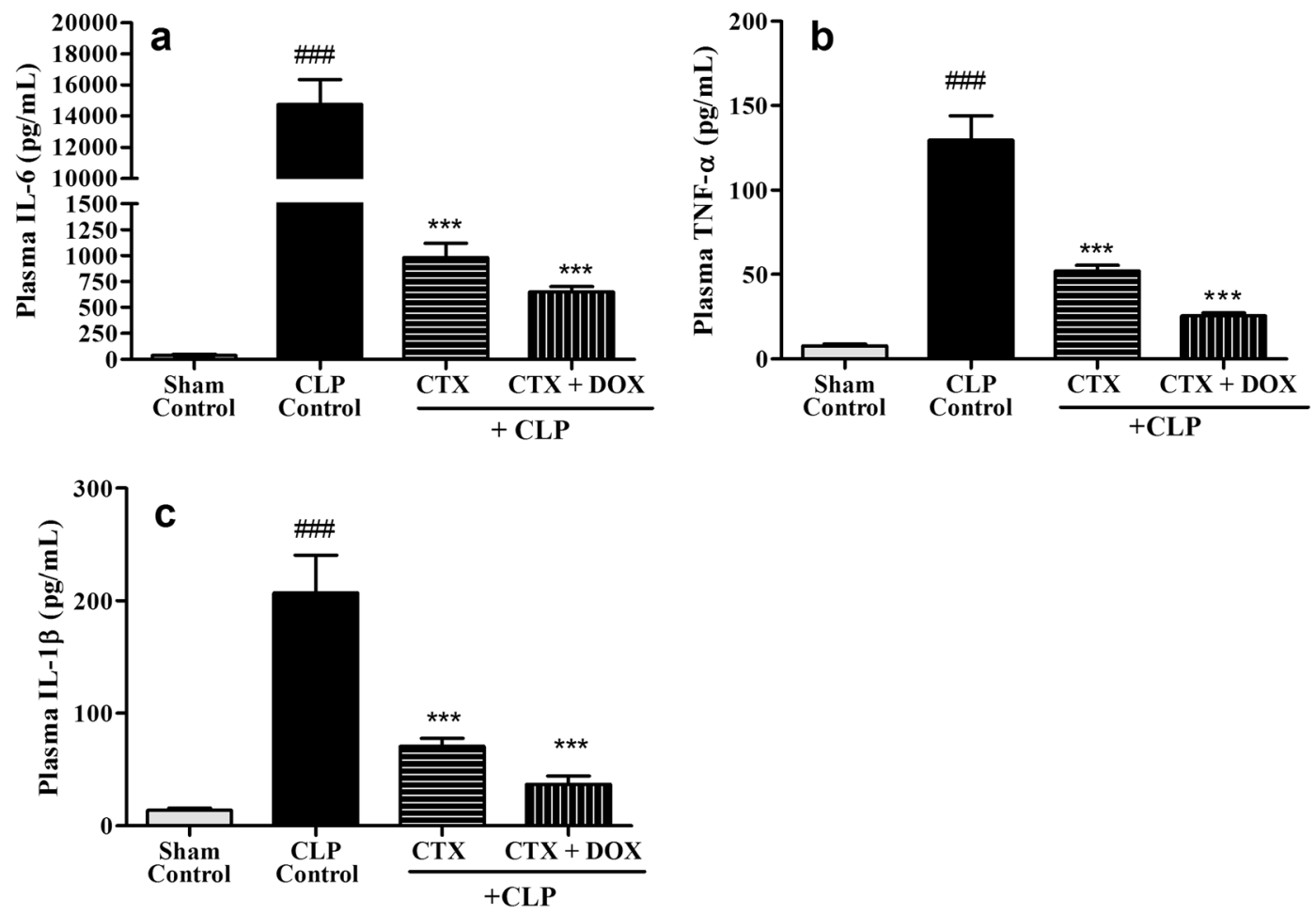

Fig. 2. Effect of doxycycline (DOX) in combination with ceftriaxone (CTX) on plasma IL-6 (a), TNF- $\alpha$ (b) and IL-1 $\beta$ (c) levels in CLP mice. Mice ( $n=6 /$ group) were treated with vehicle (saline), ceftriaxone $(100 \mathrm{mg} / \mathrm{kg}$, s.c.) alone or ceftriaxone $(100 \mathrm{mg} / \mathrm{kg}$, s.c.) in combination with doxycycline $(50 \mathrm{mg} / \mathrm{kg}$, i.p.) and plasma cytokine levels were estimated $18 \mathrm{~h}$ post-CLP challenge. Data are expressed as mean $\pm \mathrm{SEM} .{ }^{\#} P<0.05$ or ${ }^{\# \# \#} P<0.001$ for significance versus sham control. $* P<0.05, * * P<0.01$ or $* * * P<0.001$ for significance versus CLP control group. 

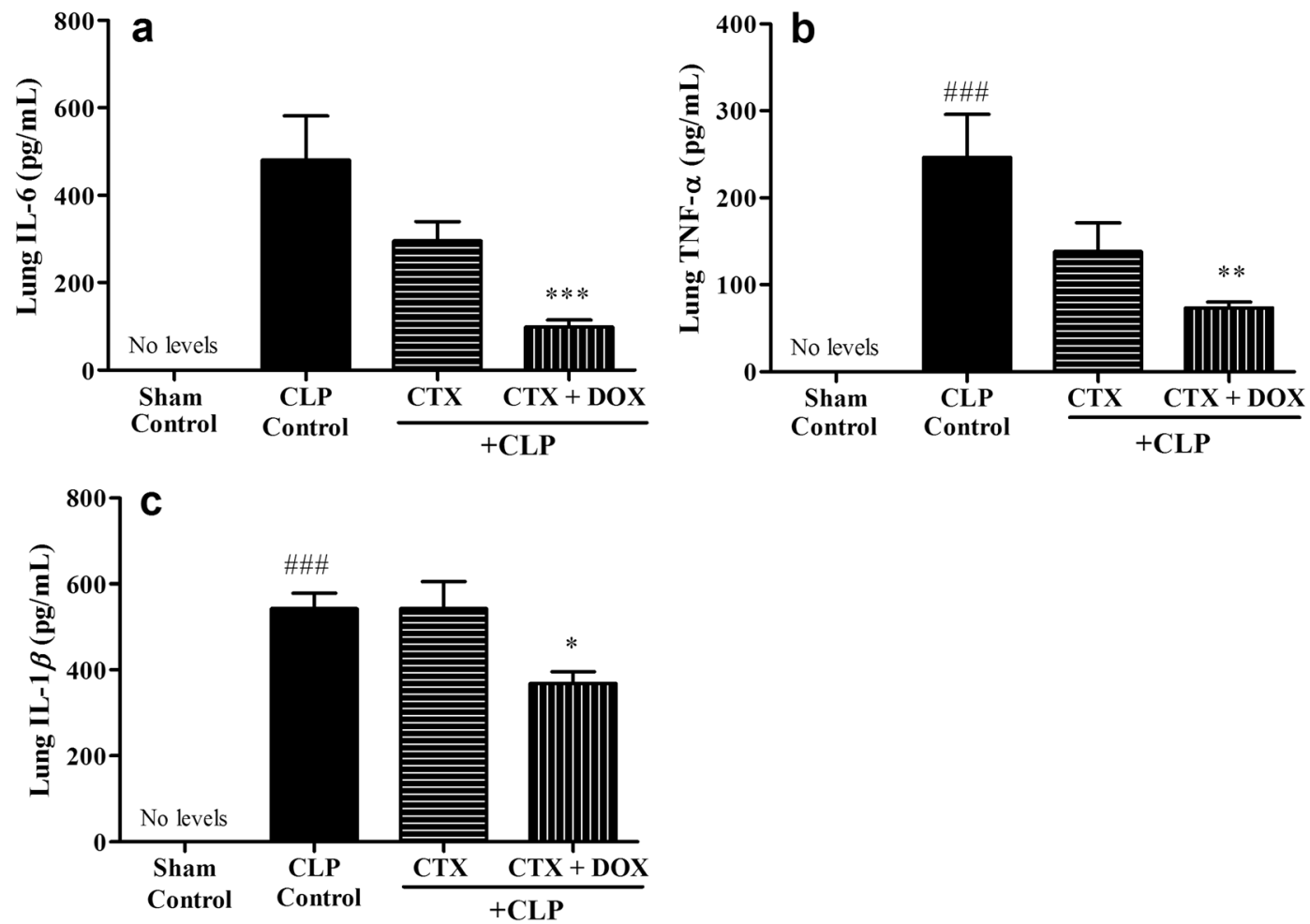

Fig. 3. Effect of doxycycline (DOX) in combination with ceftriaxone (CTX) on lung IL-6 (a), TNF- $\alpha$ (b) and IL-1 $\beta$ (c) levels in CLP mice. Mice $(n=6 /$ group) were treated with vehicle (saline), ceftriaxone $(100 \mathrm{mg} / \mathrm{kg}$, s.c.) alone or ceftriaxone $(100 \mathrm{mg} / \mathrm{kg}$, s.c.) in combination with doxycycline $(50 \mathrm{mg} / \mathrm{kg}$, i.p.) and lung cytokine levels were estimated $18 \mathrm{~h}$ post-CLP challenge. Data are expressed as mean $\pm \mathrm{SEM}$. $* * P<0.01$ for significance versus $\mathrm{CLP}$ control group.

[27]. Augmented levels of oxidative enzyme such as MPO and low levels of endogenous antioxidant such as GSH are also known as key contributors of tissue damage [28]. MPO is peroxidase enzyme abundantly expressed in neutrophils and released at the infection site following chemotaxis. It causes tissue damage by producing reactive oxygen species, promoting release of pro-inflammatory cytokines and stimulating migration neutrophils to the site of infection [29]. Pia Villa et al. had earlier demonstrated that depletion of GSH in CLP-challenged mice inhibited migration of neutrophils into peritoneal fluid that largely favoured bacterial growth, promoted neutrophil infiltration into lung, all of which significantly contributed to higher mortality rate [30].

In our study, the immunomodulatory benefit of doxycycline $(50 \mathrm{mg} / \mathrm{kg})$ in presence of ceftriaxone $(100 \mathrm{mg} / \mathrm{kg})$ was evident from suppression of CLP-induced surge in plasma and lung levels of inflammatory markers (TNF- $\alpha$, IL-1 $\beta$ and IL-6). Doxycycline also subdued CLP-induced spike in plasma and lung MPO levels and drop in plasma GSH level. These findings corroborated the significant survival observed with the doxycycline and ceftriaxone combination group challenged with CLP.

Doxycycline is a broad spectrum bacteriostatic antibiotic. Doxycycline was first investigated in LPSinduced sepsis model to assess the immunomodulatory effect and also to choose an appropriate dose to employ in CLP-induced sepsis model. Among the three single doses $(25,50$ and $100 \mathrm{mg} / \mathrm{kg})$ in the LPS sepsis model, both 50 and $100 \mathrm{mg} / \mathrm{kg}$ provided survival benefit and associated immunomodulatory activity. We hypothesised that being a broad spectrum antibiotic, doxycycline 50 and $100 \mathrm{mg} / \mathrm{kg}$ doses would provide significant survival benefit in CLP model owing to its infection control and immunomodulatory properties. However, both the doses did not exhibit significant survival benefit prompting us to combine with subprotective dose of ceftriaxone. Though doxycycline is inhibitory (bacteriostatic) to enteric bacteria, it is devoid of bactericidal activity which might be the reason for lack of much needed infection control in acute CLP 

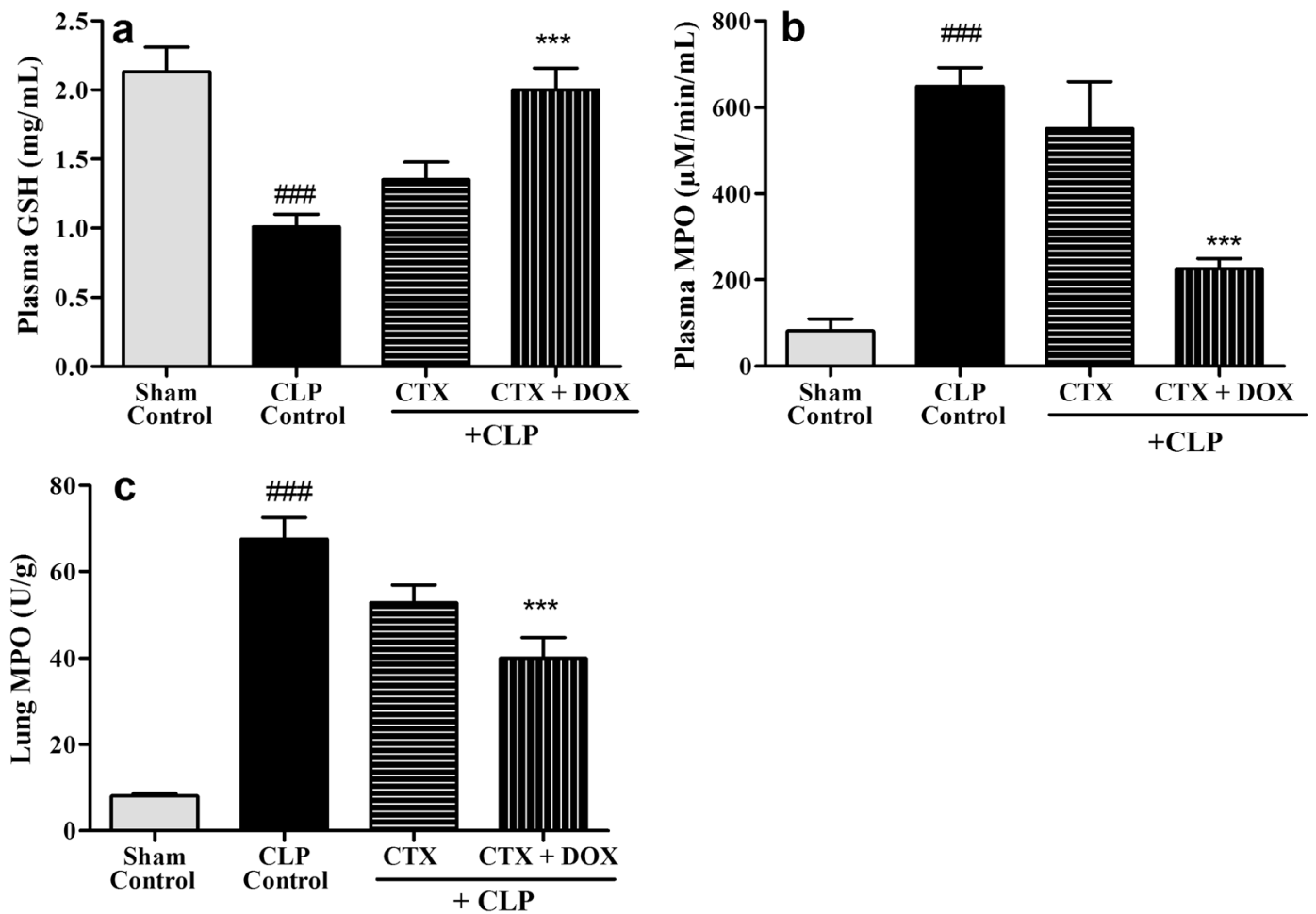

Fig. 4. Effect of doxycycline (DOX) in combination with ceftriaxone (CTX) on plasma GSH (a), plasma MPO (b) and lung MPO (c) levels in CLP mice. Mice ( $n=8 /$ group) were treated with vehicle (saline), ceftriaxone $(100 \mathrm{mg} / \mathrm{kg}$, s.c.) alone or ceftriaxone $(100 \mathrm{mg} / \mathrm{kg}$, s.c.) in combination with doxycycline $\left(50 \mathrm{mg} / \mathrm{kg}\right.$, i.p.) and plasma GSH, plasma and lung MPO were estimated $18 \mathrm{~h}$ post-CLP challenge. Data are expressed as mean \pm SEM. ${ }^{\# \# \#} P<0.001$ for significance versus sham control. $* * * P<0.001$ for significance versus CLP control group.

sepsis model. The doxycycline $50 \mathrm{mg} / \mathrm{kg}$ dose in combination with ceftriaxone $100 \mathrm{mg} / \mathrm{kg}$ dose demonstrated remarkable immunomodulatory activity. The standalone ceftriaxone did not provide significant survival benefit but there was a bacterial load reduction in surviving animals. Ceftriaxone alone produced significant reduction in plasma cytokines but had no effect on lung cytokines and MPO as well as on plasma MPO and GSH levels. The reduction in plasma cytokines was attributed to infection control which as such did not
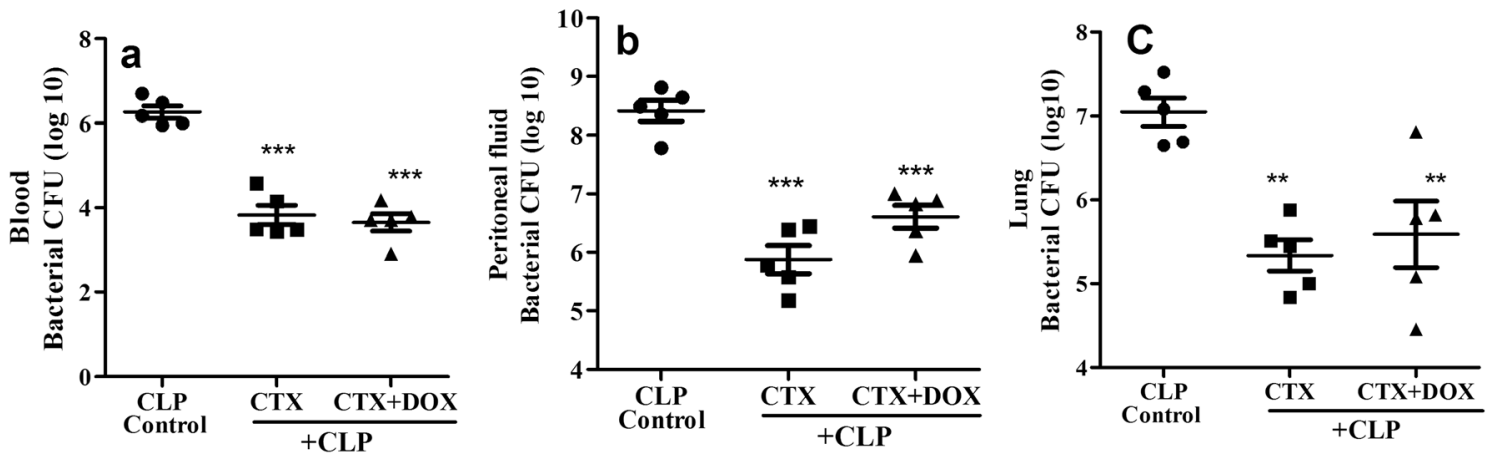

Fig. 5. Effect of doxycycline (DOX) in combination with ceftriaxone (CTX) on the bacterial count in blood (a), peritoneal lavage fluid (b) and lung (c) in CLP mice. Mice ( $n=5 /$ group) were treated $3 \mathrm{~h}$ post-CLP challenge with vehicle (saline) or ceftriaxone $(100 \mathrm{mg} / \mathrm{kg}$, s.c.) or ceftriaxone $(100 \mathrm{mg} / \mathrm{kg}$, s.c.) plus doxycycline $(50 \mathrm{mg} / \mathrm{kg}$, i.p.) and the bacterial counting was done at $18 \mathrm{~h}$ after CLP challenge. Data are expressed as mean $\pm \mathrm{SEM}$. $* * * P<0.001 \mathrm{for}$ significance versus CLP control group. 
lead to survival benefit. The combination group not only suppressed the plasma levels of cytokine, MPO and GSH but also had significant effect on the lung cytokine and MPO levels. These observations confirmed that infection control in conjunction with immunomodulatory effect is necessary for survival. Interestingly, the highest dose of doxycycline $100 \mathrm{mg} / \mathrm{kg}$ in combination with ceftriaxone did not result in dose dependant improved survival rather mortality rate was not different than that of CLP control group. This observation cannot be readily attributable to toxicity as LPS-treated or CLP-untreated mice tolerated this dose. Further investigation is required to understand this aspect of doxycycline. As we highlight the beneficial effect of doxycycline, it should be noted that our study employed only a single administration of doxycycline. Since the CLP model was very acute, studying the multiple doses was not feasible. Further, assessing the effect of doxycycline in later phase of sepsis was also not practicable. Moreover, doxycycline's ineffectiveness in absence of ceftriaxone also should be noted.

Since doxycycline is a clinically approved antibiotic, our study supports investigation on its beneficial effect in clinical sepsis. Considering the inhibitory effect of doxycycline on key pro-inflammatory cytokines involved in sepsis, the anti-inflammatory effect of doxycycline in this model appears to be driven by inhibition of NF-KB signalling pathway. Besides this, the amelioration of lung injury due to doxycycline inhibitory effect on MMP-9 could not be ruled out. These assumptions need to be confirmed through actual studies.

In the CLP-induced sepsis model, doxycycline demonstrated improved survival through immunomodulatory effect. As a result of this activity, doxycycline could offer therapeutic benefits in attenuating the acute lung injury due to inflammatory responses in sepsis

\section{ACKNOWLEDGMENTS}

We thank the Wockhardt Research Centre, India, and Dr. Mahesh Patel for granting permission for performing these studies.

Funding Information This work was self-funded.

\section{COMPLIANCE WITH ETHICAL STANDARDS}

This study protocols were approved by Institutional animal ethics committee of Wockhardt Research Centre, India, registered under Committee for the Purpose of
Control and Supervision of Experiments on Animals (CPCSEA), India.

Conflict of Interest. The authors declare that they have no conflict of interest.

\section{REFERENCES}

1. Varisco, B.M. 2011. The pharmacology of acute lung injury in sepsis. Advances in Pharmacological Sciences 2011: 254619.

2. Kim, W.Y., and S.B. Hong. 2016. Sepsis and acute respiratory distress syndrome: recent update. Tuberculosis Respiratory Disease 79: 53-57.

3. Fahmi, A.N.A., G.S.G. Shehatou, and H.A. Salem. 2018. Levocetirizine pretreatment mitigates lipopolysaccharide-induced lung inflammation in rats. BioMed Research International 2018: 7019759.

4. Aziz, M., A. Jacob, W.L. Yang, A. Matsuda, and P. Wang. 2013. Current trends in inflammatory and immunomodulatory mediators in sepsis. Journal of Leukocyte Biology 93: 329-342.

5. Cavaillon, J.M., M. Adib-Conquy, C. Fitting, C. Adrie, and D. Payen. 2003. Cytokine cascade in sepsis. Scandinavian Journal of Infectious Diseases 35: 535-544.

6. Harsha, N., P. Shuyu, and K. Cuk-Seong. 2018. Role of mitochondrial oxidative stress in sepsis. Acute and Critical Care 33: 65-72.

7. Zhang, J., J. Bi, S. Liu, Q. Pang, R. Zhang, S. Wang, and C. Liu. 2017. 5-HT drives mortality in sepsis induced by cecal ligation and puncture in mice. Mediators of Inflammation 2017: 1-12.

8. Steckert, A.V., A.A. de Castro, J. Quevedo, and Dal-Pizzol. 2014. Sepsis in the central nervous system and antioxidant strategies with $\mathrm{N}$-acetylcysteine, vitamins and statins. Current Neurovascular Research 11: 83-90.

9. Ng, H.H., T. Narasaraju, M.C. Phoon, M.K. Sim, J.E. Seet, and V.T. Chow. 2012. Doxycycline treatment attenuates acute lung injury in mice infected with virulent influenza H3N2 virus: involvement of matrix metalloproteinases. Experimental and Molecular Pathology 92: 287-295.

10. Davey, A., D.F. McAuley, and C.M. O'Kane. 2011. Matrix metalloproteinases in acute lung injury: mediators of injury and drivers of repair. European Respiratory Journal 38: 959-970.

11. Hutchins, N.A., J. Unsinger, R.S. Hotchkiss, and A. Ayala. 2014. The new normal: immuno-modulatory agents against sepsis immune suppression. Trends in Molecular Medicine 20: 224-233.

12. Pasquale, R., and S. Tan. 2005. Nonantimicrobial effects of antibacterial agents. Clinical Infectious Diseases 40: 127-135.

13. Shapira, L., W.A. Soskolne, Y. Houri, V. Barak, A. Halabi, and A. Stabholz. 1996. Protection against endotoxic shock and lipopolysaccharide- induced local inflammation by tetracycline: correlation with inhibition of cytokine secretion. Infection and Iттиnity 64: 825-828.

14. Sapadin, A.N., and R. Fleischmajer. 2006. Tetracyclines: nonantibiotic properties and their clinical implications. Journal of the American Academy of Dermatology 54: 258-265.

15. Milano, S., F. Arcoleo, P. D'Agostino, and E. Cillari. 1997. Intraperitoneal injection of tetracyclines protects mice from lethal endotoxemia downregulating inducible nitric oxide synthase in 
various organs and cytokine and nitrate secretion in blood. Antimicrobial Agents and Chemotherapy 41: 117-121.

16. D'Agostino, P., M. La Rosa, C. Barbera, F. Arcoleo, G. Di Bella, S. Milano, and E. Cillari. 1998. Doxycycline reduces mortality to lethal endotoxemia by reducing nitric oxide synthesis via an interleukin10-independent mechanism. Journal of Infectious Diseases 177: 489-492.

17. Sun, J., H. Shigemi, Y. Tanaka, T. Yamauchi, T. Ueda, and H. Iwasaki. 2015. Tetracyclines downregulate the production of LPSinduced cytokines and chemokines in THP-1 cells via ERK, p38, and nuclear factor- $\mathrm{kB}$ signaling pathways. Biochemistry and Biophysics Reports 4: 397-404.

18. Fujita, M., Q. Ye, H. Ouchi, E. Harada, I. Inoshima, K. Kuwano, and Y. Nakanishi. 2006. Doxycycline attenuated pulmonary fibrosis induced by bleomycin in mice. Antimicrobial Agents and Chemotherapy 50: 739-743.

19. Muri, L., M. Perny, J. Zemp, D. Grandgirard, and S.L. Leib. 2019. Combining ceftriaxone with doxycycline and daptomycin reduces mortality, neuroinflammation, brain damage, and hearing loss in infant rat pneumococcal meningitis. Antimicrobial Agents and Chemotherapy 63: e00220-e00219.

20. Fredeking, T.M., J.E. Zavala-Castro, P. González-Martínez, W. Moguel-Rodríguez, E.C. Sanchez, M.J. Foster, and F.A. DiazQuijano. 2015. Dengue patients treated with doxycycline showed lower mortality associated to a reduction in IL-6 and TNF levels. Recent Patents on Anti-Infective Drug Discovery 10: 51-58.

21. Dejager, L., I. Pinheiro, E. Dejonckheere, and C. Libert. 2011. Cecal ligation and puncture: the gold standard model for polymicrobial sepsis? Trends in Microbiology 19: 198-208.

22. Remick, D.G., D.E. Newcomb, G.L. Bolgos, and D.R. Call. 2000. Comparison of the mortality and inflammatory response of two models of sepsis: lipopolysaccharide vs cecal ligation and puncture. Shock 13: 110-116.

23. Patel, A., J. Joseph, H. Periasamy, and S. Mokale. 2018. Azithromycin in combination with ceftriaxone reduces systemic inflammation and provides survival benefit in a murine model of polymicrobial sepsis. Antimicrobial Agents and Chemotherapy 62: e00752-e00718.

24. Ebong, S., D. Call, J. Nemzek, G. Bolgos, D. Newcomb, and D. Remick. 1999. Immunopathologic alterations in murine models of sepsis of increasing severity. Infection and Immunity 67: 6603-6610.

25. Won-Young, K., and H. Sang-Bum. 2016. Sepsis and acute respiratory distress syndrome: recent update. Tuberculosis Respiratory Disease (Seoul) 79: 53-57.

26. Wibke, S., B. Jürgen, and B. Richard. 2013. Cytokines in sepsis: potent immunoregulators and potential therapeutic targets - an updated view. Mediators of Inflammation 2013: 165974.

27. Fjell, C.D., S. Thair, J.L. Hsu, K.R. Walley, J.A. Russell, and J. Boyd. 2013. Cytokines and signalling molecules predict clinical outcomes in sepsis. PLoS One 8: e79207.

28. Sener, G., H. Toklu, C. Kapucu, F. Ercan, G. Erkanli, A. Kaçmaz, M. Tilki, and B.C. Yeğen. 2005. Melatonin protects against oxidative organ injury in a rat model of sepsis. Surgery Today 35: 52-59.

29. Haegens, A., J.H. Vernooy, P. Heeringa, B.T. Mossman, and E.F, Wouters. 2008. Myeloperoxidase modulates lung epithelial responses to pro-inflammatory agents. The European Respiratory Journal 31: 252-260.

30. Villa, P., A. Saccani, A. Sica, and P. Ghezzi. 2002. Glutathione protects mice from lethal sepsis by limiting inflammation and potentiating host defense. The Journal of Infectious Diseases 185: 1115-1120. 